\title{
Dietary Effects of Magnesium on Histamine Metabolism and Urine Acidity in Domestic Felines
}

\author{
Sarah K. Martin, David L. Harmon, Charlotte E. Conway, Eric S. Vanzant and Kyle R. McLeod \\ Department of Food and Animal Sciences, College of Agriculture, University of Kentucky, Lexington, KY, US
}

Received 2012-10-26, Revised 2012-11-29; Accepted 2012-12-29

\begin{abstract}
Magnesium deficiency has been associated with increased histamine production in rats. Limitation of $\mathrm{Mg}$ with acidifying foods is common practice for management of urinary tract health in domestic cats. Nine healthy adult female shorthair cats were used in a 3 period random crossover experiment with fixed treatment sequences to test the effects of dietary $\mathrm{Mg}(0.06,0.12$ and $0.18 \% \mathrm{DM})$ on histamine in blood and urine. The dry-extruded test foods were fed in sufficient amounts to maintain ideal body weight and obtain a target urine $\mathrm{pH}$ of 6.3. Each experimental period was preceded by a $7 \mathrm{~d}$ wash out period, in which the $0.06 \% \mathrm{Mg}$ food was fed, followed by a $14 \mathrm{~d}$ feeding period of the appropriate food. Two $24 \mathrm{~h}$ total urine collections were performed (d13: Acidified, d14: Un-acidified; immediately iced) and blood was collected on d14. Dry matter intake ( $\mathrm{p} \geq 0.13)$ and $\mathrm{BW}(\mathrm{p} \geq 0.13)$ were not affected by treatment. Plasma $\mathrm{Mg}$ concentration increased linearly with increasing dietary $\mathrm{Mg}$ $(0.54,0.56,0.58 \mathrm{mM} ; \mathrm{p}=0.001)$. In contrast, plasma concentrations of threonine, histidine and tryptophan were lower in cats fed $0.12 \% \mathrm{Mg}$ compare with 0.06 or $0.18 \% \mathrm{Mg}$ (quadratic, $\mathrm{p} \leq 0.03$ ). Urine output ( $\mathrm{p} \geq 0.17), \mathrm{pH}(\mathrm{p} \geq 0.55), \mathrm{NH}_{3}(\mathrm{p} \geq 0.21)$ and titratable acidity of urine $(\mathrm{p} \geq 0.14)$ were similar across treatments. Urinary histamine excretion responded quadratically $(p=0.02)$ to treatment $(3483,3369$, $3986 \mathrm{ng} / \mathrm{d})$, whereas urinary histamine: Creatinine $(\mathrm{p} \geq 0.43)$ and plasma histamine concentration $(\mathrm{p} \geq 0.55)$ were unaffected. Differences were not detected among treatments in total histamine, cellular + noncellular histamine, $(\mathrm{p} \geq 0.11)$ or antigen-induced $(\mathrm{p} \geq 0.21)$ histamine release in whole blood. These data indicate that dietary $\mathrm{Mg}$ concentration, from $0.06-0.18 \%$, does not affect urinary acidity or circulating histamine concentrations, however, supplying $\mathrm{Mg}$ at $0.18 \%$ may increase urinary histamine excretion.
\end{abstract}

Keywords: Cat, Magnesium, Histamine, Urine

\section{INTRODUCTION}

Urine acidifying diet interventions are frequently used to manage and treat magnesium ammonium phosphate hexahydrate (struvite) crystal formation in domestic felines (Matsui, 2007). Super-saturation of magnesium, phosphate and ammonium ions in urine can lead to struvite formation, but urine alkalinity is a better predictor of struvite formation than dietary Mg (Bartges and Kirk, 2006). Nevertheless, it is common practice to control $\mathrm{Mg}$ content in feline maintenance diets to as little as 0.05 to $0.3 \%$ for label claims of "urinary tract health" (Matsui, 2007). Magnesium has been implicated in modulating cellular events involved in inflammation and limited $\mathrm{Mg}$ has been associated with increased histamine production in rats (Malpuech-Brugere, 2000; Mazur et al., 2007). The requirement for $\mathrm{Mg}$ in the adult domestic feline is $200 \mathrm{mg} \mathrm{kg}^{-1}$ diet or $0.02 \%$ (NRC, 2003). However few data demonstrate the effects of dietary $\mathrm{Mg}$ on feline inflammatory status or relationship between dietary $\mathrm{Mg}$ and feline lower urinary tract disease incidence. If dietary $\mathrm{Mg}$ can affect the inflammatory status of the domestic feline, it may be important to more closely evaluate the advantages and disadvantages of limiting $\mathrm{Mg}$ in the diet to prevent struvite formation. This experiment tested the hypothesis that low levels of dietary $\mathrm{Mg}$ would cause alterations in histamine dynamics, resulting in elevated urinary histamine concentration.

Corresponding Author: K.R. McLeod, Department of Animal and Food Sciences, College of Agriculture University of Kentucky, 806 W.P. Garrigus Bldg., Lexington, KY 40546-0215, US 


\section{MATERIALS AND METHODS}

\subsection{Animals}

Nine domestic shorthaired spayed female cats $(3.8 \pm 0.14 \mathrm{~kg} \mathrm{BW})$ between 3 to 4 years were utilized in this experiment. Cats were housed in individual cages at Spindletop Research Unit (University of Kentucky, Lexington, KY) and maintained at an ambient temperature of $25^{\circ} \mathrm{C}$ with a $16 \mathrm{~h}$ light $/ 8 \mathrm{~h}$ dark cycle. Animals were confined to cages during feeding periods and at night. Enrichment and social time was provided between feeding periods. Felines had ad libitum access to water and were fed a complete and balanced adult maintenance diet to maintain ideal body weight (Hill's Science Diet, Adult Maintenance Formula) prior to each experimental period and during inter-experimental periods. Animals were fed at 0730 and 1930. The experiment was performed as a random crossover design with fixed treatment sequences to test effects of dietary magnesium $(0.06 \%, 0.12 \%$ and $0.18 \% \mathrm{Mg}$ DM). Each experimental period consisted of a 9d "pre-feed" or "wash out" period, during which time the animals received adult maintenance diet, fed to maintain ideal body weight. Following each "wash-out" period, a one d dietary transition was performed in which cats were provided $50 \%$ adult maintenance and $50 \%$ test diet. The first day after the diet transition was considered $\mathrm{d}$ 1 of a 14-d feeding period, during which time the cats received assigned test diet (Table 1). Refusals were collected at 0730 daily, weighed, recorded and discarded. Representative feed samples were obtained from each $9.1 \mathrm{~kg}$ bag opened during the experiment for dry matter analysis. After d 14 of each feeding period, animals underwent a one day diet transition back to adult maintenance diet and were maintained thusly for $7 \mathrm{~d}$ as a "wash out."

\subsection{Total Urine Collection}

On d 12, 13 and 14, cats were confined to their individual cages for urine collection. Urine was collected via Smart Cat Box Collection System (Providence House Mfg. Inc., Seal Rock, OR). This system utilized a grated tray containing polyethylene beads (Smart Cat Box, Providence House Mfg. Inc., Seal Rock, OR) (cat litter substitute) which drained into a lower tray equipped with a funneled floor and drain. These boxes are fashioned to function with a urine reservoir; however, the needs of this collection required that the urine samples be immediately preserved over ice, post elimination. In order to achieve this, the central hole which would normally drain to a urine reservoir was permanently attached to a $33 \mathrm{~mm}$ laboratory funnel.
Table 1. Ingredients of experimental diets (dry matter basis) $\%$ Dietary magnesium

\begin{tabular}{lrrr} 
& 0.06 & 0.12 & 0.18 \\
\hline Ingredient (\%) & 47.77 & 47.67 & 47.57 \\
Brewers rice & 26.10 & 26.10 & 26.10 \\
Corn gluten meal & 11.00 & 11.00 & 11.00 \\
Choice white grease & 3.67 & 3.67 & 3.67 \\
Pork by-product meal & 2.30 & 2.30 & 2.30 \\
Fish meal & 2.24 & 2.24 & 2.24 \\
Lamb meal & 0.80 & 0.80 & 0.80 \\
Fish oil & 1.50 & 1.50 & 1.50 \\
Palatability enhancer & 0.40 & 0.40 & 0.40 \\
L-Threonine & 0.25 & 0.25 & 0.25 \\
Taurine & 0.15 & 0.15 & 0.15 \\
DL-Methionine & 0.13 & 0.13 & 0.13 \\
L-Lysine-HCl & 0.05 & 0.05 & 0.05 \\
L-Tryptophan & 1.00 & 1.00 & 1.00 \\
Potassium chloride & 0.70 & 0.70 & 0.70 \\
Calcium sulfate & 0.53 & 0.53 & 0.53 \\
Choline chloride & 0.35 & 0.35 & 0.35 \\
Salt, Iodized & 0.30 & 0.30 & 0.30 \\
Dicalcium phosphate & 0.18 & 0.18 & 0.18 \\
Potassium sulfate & -- & 0.10 & 0.20 \\
Magnesium oxide & 0.31 & 0.31 & 0.31 \\
Vitamin E & 0.10 & 0.10 & 0.10 \\
Vitamin premix & 0.10 & 0.10 & 0.10 \\
Mineral premix & 0.07 & 0.07 & 0.07 \\
Preservative & & &
\end{tabular}

Funnel was fitted to $46 \mathrm{~cm}$ BARD urine collection tubing (C.R. BARD, Inc., Covington, GA). Tubing exited the cage into a Styrofoam cooler, through a hole drilled into the side, approximately $5-10 \mathrm{~cm}$ from the bottom of the cooler. The tubing was attached to a 265 $\mathrm{mL}$ BARD Urine Collection bag (C.R. BARD, Inc., Covington, GA), inside the cooler, preserved on ice. Samples were collected such that starting on $\mathrm{d} 12$; cats were given $24 \mathrm{~h}$ to urine void. If after $24 \mathrm{~h}$, no void was produced, the first urinary elimination was collected and considered to be the first $24 \mathrm{~h}$ urine void. After the first sample was collected, urine collection bags were acidified with $5 \mathrm{~mL}$ of $6 \mathrm{~N} \mathrm{HCl}$ and were preserved over ice. Acidified urine samples were collected in the same manner as those, not acidified, with $24 \mathrm{~h}$ provided and if no sample produced after $24 \mathrm{~h}$, the first elimination considered the second $24 \mathrm{~h}$ urine void.

Non-acidified urine samples were assessed immediately for $\mathrm{pH}$ and titratable acidity. Titratable acidity was determined from aliquots of urine sample and titrated via the addition of $0.1 \mathrm{M} \mathrm{NaOH}$ until a sustained $\mathrm{pH}$ of 7.4 was attained. The amount of $\mathrm{NaOH}$ required to titrate the sample was recorded and reported as a proportion of the aliquot size $(\mathrm{mL} \mathrm{NaOH} / \mathrm{mL}$ urine). Acidified urine samples were aliquoted into $12 \times 75 \mathrm{~mm}$ polyethylene tubes or $1.5 \mathrm{~mL}$ micro-centrifuge tubes and stored at $-20^{\circ} \mathrm{C}$ until assayed. 
Table 2. Proximate analysis and magnesium content of experimental diets (dry matter basis)

\begin{tabular}{llrr}
\hline & \% Dietary magnesium & \\
Analyte (\%) & 0.06 & 0.12 & 0.18 \\
\hline Crude protein & 27.60 & 27.8 & 28.50 \\
Crude fat & 16.40 & 18.3 & 15.80 \\
Crude fiber & 1.20 & 0.8 & 1.40 \\
Ash & 5.10 & 5.3 & 5.50 \\
Magnesium & 0.07 & 0.1 & 0.17 \\
\hline
\end{tabular}

\subsection{Blood Sampling and Handling}

On d14 of experimental period, cats were sedated with Torbugesic $\left(0.01 \mathrm{mg} \mathrm{kg}^{-1} \mathrm{BW}\right.$, Fort Dodge, Pfizer Animal Health, Wyeth) and Dormitor $\left(40 \mu \mathrm{g} \mathrm{kg}^{-1} \mathrm{BW}\right.$ Pfizer Animal Health, Exton, PA). Blood samples (8 mL) were drawn from the jugular vein, placed into heparinized (23.5 IU per $\mathrm{mL}$ heparin sulfate) tubes, a $1 \mathrm{~mL}$ aliquot was placed into a $1.5 \mathrm{~mL}$ micro-centrifuge tube and maintained at room temperature for $1-2 \mathrm{~h}$ for histamine release ELISA, while remaining $7 \mathrm{~mL}$ were stored on ice until centrifuged at $7,000 \times \mathrm{g}$ for $15 \mathrm{~min}$ and plasma harvested and stored for analysis $\left(-20^{\circ} \mathrm{C}\right)$.

\subsection{Chemical Analysis of Diets}

Diets were analyzed (Table 2) for moisture (930.15), ash (942.05), crude fat (954.02), crude fiber (962.09) and magnesium (968.08) content according to the (AOAC, 2005). Crude protein content of the diets was determined using a Leco CN2000 nitrogen analyzer (Leco Corp., St. Joseph, MI).

\subsection{Plasma Magnesium}

One milliliter plasma samples were transported on ice and immediately analyzed (within 2-4 h of sample collection) post centrifugation for $\mathrm{Mg}$ concentration with Nova 8 Electrolyte/Chemistry Analyzer (NOVA Biomedical Corp, Waltham, MA).

\subsection{Histamine ELISA}

Histamine ELISA kits (Ref \#: BA 10-1000; Rocky Mountain Diagnostics, Colorado Springs, CO) were utilized for the determination of histamine concentration of plasma, urine and whole blood. Urine samples were diluted 1:9 with provided diluent. Plasma samples were de-proteinized with $1 \%$ Tricholoacetic acid solution; $0.150 \mathrm{~mL}$ plasma and $0.150 \mathrm{~mL} 1 \%$ TCA combined in micro-centrifuge tube, vortexed for $30 \mathrm{sec}$ and submerged in an ice water bath for $5 \mathrm{~min}$. Samples were centrifuged at $18,000 \times \mathrm{g}$ for $10 \mathrm{~min}$ at $4^{\circ} \mathrm{C}$. Supernatant was utilized for determination of histamine in plasma. Histamine Release kits (Ref \#: BA 10-1100; Rocky Mountain Diagnostics, Colorado Springs, CO) were utilized in conjunction with Histamine ELISA kit for in vitro determination of histamine release capacity in heparinized whole blood. Total histamine (intracellular + extracellular) was measured in heparinized whole blood and represented the total concentration $(\mathrm{mg} / \mathrm{dL})$ of histamine in a representative sample. Total histamine release was determined by incubating whole blood in releasing buffer in the presence of anti-IgE. Spontaneous histamine release was measured by incubating whole blood in releasing buffer without the addition of whole blood. Basophilic granulocytes are the primary cells in blood that contain and release histamine (Galoppin et al., 1989). Thus, in vitro total release represents the induced release of histamine from basophils and spontaneous release is the fraction that is released or leaked in the absence of antigen.

\subsection{Urine Ammonia}

Previously acidified urine samples were thawed and vortexed thoroughly. Samples were diluted 500:1 with distilled water in $10 \mathrm{~mL}$ polyethylene test tubes and vortexed for $30 \mathrm{sec}$. Ammonia concentration was determined enzymatically using a Konelab Analyzer (Thermo Electron Corp., Vantaa, Finland).

\subsection{Urine Creatinine}

Acidified urine samples were used in an enzymatic method to determine concentration of creatinine in which creatinine was converted to creatine under the activity of creatininase (Myers, 2006). Creatine was then acted upon by creatinase to form sarcosine and urea. Sarcosine oxidase converted sarcosine to glycine and hydrogen peroxide and the hydrogen peroxide reacted with a chromophore in the presence of peroxidase to produce a colored product that was measured at $546 \mathrm{~nm}$ (secondary wavelength $=700 \mathrm{~nm} ;$ Roche/Hitachi Modular Analytical System, Roche, Basel, Switzerland).

\subsection{Determination of Total Amino Acids in Plasma}

Plasma amino acids were determined by isotope dilution with Gas Chromatography-Mass Spectrometry (GC-MS) as previously described (Calder et al., 1999; El-Kadi et al., 2006). To a known weight (0.5 g) of fresh plasma was added an equal known weight of a solution containing $0.2 \mathrm{mg}$ hydrolyzed $\left[\mathrm{U}^{-13} \mathrm{C}\right]$ algae protein powder (99 atoms \%; Martek Biosciences, Waltham, MD), $100 \mathrm{nmol}$ [indole- ${ }^{2} \mathrm{H}_{5}$ ] tryptophan, $200 \mathrm{nmol}[5-$ ${ }^{15} \mathrm{~N}$ ] glutamine, $25 \mathrm{nmol}$ [methyl- ${ }^{2} \mathrm{H}_{3}$ ] methionine and 3 $\mu \mathrm{mol}[15 \mathrm{~N} 2]$ urea and the samples stored frozen $\left(-80^{\circ} \mathrm{C}\right)$.

Thawed samples were de-proteinized by addition $(1 \mathrm{~mL})$ of sulfosalicylic acid $(15 \% \mathrm{w}: \mathrm{v})$, the supernatant desalted by cation (AG-50, $\mathrm{H}+$ form) exchange and amino acids and urea eluted with $2 \mathrm{~mol} / \mathrm{L} / \mathrm{NH}_{4} \mathrm{OH}$ 
followed by water. Eluate was lyophilized to dryness and amino acids converted to their t-butyldimethylsilyl derivative. Under electron impact mode, the following ions $(\mathrm{m} / \mathrm{z})$ were monitored: Urea 231, 233; alanine 260, 263; glycine 246, 248; valine 288, 293; isoleucine 302, 308; praline 286, 291; methionine 292, 295; serine 390, 393; threonine 404, 408; phenylalanine 234, 242; aspartate 302, 304; glutamate 432, 437; lysine 300, 306; histidine 440, 446; glutamine 168, 169; tyrosine 302, 304; and tryptophan 244, 249. For leucine isotope enrichment and concentration, ions at 302, 303 ([1- $\left.{ }^{13} \mathrm{C}\right]$ leucine), $305\left(\left[{ }^{2} \mathrm{H}_{3}\right]\right.$ leucine) and $308\left(\left[{ }^{13} \mathrm{C}_{6}\right]\right.$ leucine, internal standard) were monitored. Calibration curves were generated from gravimetric mixtures of labeled and unlabeled amino acid.

\subsection{For Leucine}

Correction was also made for spillover of $\left[1-{ }^{13} \mathrm{C}\right]$ leucine $(\mathrm{m} / \mathrm{z} 303)$ into $\left[{ }^{2} \mathrm{H}_{3}\right]$ leucine $(\mathrm{m} / \mathrm{z} 305)$ and spillover of $\left[{ }^{2} \mathrm{H}_{3}\right]$ leucine into $\left[{ }^{13} \mathrm{C}_{6}\right]$ leucine $(\mathrm{m} / \mathrm{z} 308)$. All enrichments were expressed as Atoms Percent Excess (APE) relative to background natural abundance (El-Kadi et al., 2006).

\subsection{Statistical Analysis}

Data were analyzed as a random crossover design with fixed treatment sequences using the MIXED procedure of SAS (version 8.0, SAS Institute). Actual magnesium concentration for each diet varied slightly from the formulation target. Thus, backward stepwise regression was performed using actual intake of magnesium, where second order model (Quadratic) was tested and if not significant, the analysis was repeated with a first order (Linear) model. All data are presented as Least
Squares Means \pm SEM. Effects were considered significant at $\mathrm{p} \leq 0.05$ and a tendency for significance at $\mathrm{p} \leq 0.10$.

\section{RESULTS}

Dry matter intake $(\mathrm{p} \geq 0.13)$ and $\mathrm{BW}(\mathrm{p} \geq 0.16)$ were not affected by treatment (Table 3). Plasma $\mathrm{Mg}$ increased linearly with increasing dietary $\mathrm{Mg}(\mathrm{p}=$ $0.001)$. Urine output $(\mathrm{p} \geq 0.17), \quad \mathrm{pH} \quad(\mathrm{p} \geq 0.55), \quad \mathrm{NH}_{3}$ $(p \geq 0.21)$ and titratable acidity of urine $(p \geq 0.14)$ were similar across treatments. Urinary histamine concentration was lower for the mid-level $\mathrm{Mg}$ diet compared with either the low-or high-level diet (Quadratic; $p=0.05$ ). Urinary histamine excretion rate responded quadratically $(\mathrm{p}=0.02)$ to increasing dietary $\mathrm{Mg}$ treatment with the high $\mathrm{Mg}$ diet having a greater excretion rate than the low and mid-level $\mathrm{Mg}$ diets. However, urinary histamine: Creatinine was similar across treatments $(\mathrm{p} \geq 0.43)$. Plasma histamine concentration ( $\mathrm{p} \geq 0.55)$ was also unaffected by dietary $\mathrm{Mg}$. Differences were not detected among treatments in total histamine, cellular + non-cellular histamine, $(\mathrm{p} \geq 0.11)$ or antigen-induced $(\mathrm{p} \geq 0.21)$ histamine release in whole blood (Table 4). Plasma lysine concentration tended to increase (linear; $p=0.09$ ) with increasing dietary levels of $\mathrm{Mg}$ (Table 5). In contrast, threonine $(p=0.01)$, histidine $(p=0.02)$ and tryptophan $(\mathrm{p}=0.03)$ demonstrated a quadratic effect with dietary treatment; and leucine $(p=0.09)$, methionine $(p=0.07)$, phenylalanine $(p=0.09)$ and aspartate $(p=0.08)$ exhibited quadratic trends with dietary treatment (Table 4). In the case of each amino acid, the quadratic response was attributable to lower plasma concentrations for the $0.12 \% \mathrm{Mg}$ diet compared with either the 0.06 or $0.18 \% \mathrm{Mg}$ diet.

Table 3. Effects of dietary magnesium on biochemical analytes of urine and plasma

\begin{tabular}{|c|c|c|c|c|c|c|}
\hline & \multicolumn{3}{|c|}{ \% Dietary Magnesium } & \multicolumn{3}{|c|}{ P Value $^{\mathrm{a}}$} \\
\hline & 0.06 & 0.12 & 0.18 & SEM $^{b}$ & Lin & Quad \\
\hline Body weight (kg) & 3.85 & 3.81 & 3.79 & 0.03 & 0.160 & 0.28 \\
\hline Dry matter intake $(\mathrm{g} / 24 \mathrm{~h})$ & 39.30 & 39.60 & 39.70 & 2.04 & 0.130 & 0.70 \\
\hline Urine Output (g/24h) & 24.90 & 28.80 & 29.00 & 2.99 & 0.170 & 0.48 \\
\hline $\mathrm{pH}$ & 6.15 & 6.22 & 6.17 & 0.05 & 0.550 & 0.95 \\
\hline $\mathrm{NH}_{3}(\mathrm{mmol} / \mathrm{L})$ & 354.30 & 313.70 & 333.50 & 19.32 & 0.440 & 0.21 \\
\hline Titratable acidity $^{\mathrm{c}}$ & 0.18 & 0.17 & 0.16 & 0.01 & 0.140 & 0.78 \\
\hline Creatinine (mg/dL) & 337.10 & 282.20 & 318.00 & 22.95 & 0.740 & 0.20 \\
\hline Histamine (ng/mL) & 140.70 & 117.60 & 138.30 & 13.86 & 0.790 & 0.05 \\
\hline Histamine: Creatinine ${ }^{\mathrm{d}, \mathrm{e}}$ & 4.34 & 4.35 & 4.38 & 0.96 & 0.720 & 0.43 \\
\hline Histamine (ng/24 h) & 3483.00 & 3369.00 & 3986.00 & 511.45 & 0.210 & 0.02 \\
\hline Plasma Histamine $(\mathrm{ng} / \mathrm{mL})$ & 1.30 & 1.00 & 1.10 & 0.38 & 0.550 & 0.76 \\
\hline Magnesium(mmol/L) & 0.54 & 0.56 & 0.58 & 0.01 & 0.001 & 0.48 \\
\hline
\end{tabular}

a; Probability of larger F-statistic; ${ }^{\text {b; }} \mathrm{n}=9 ;{ }^{\mathrm{c} ;} \mathrm{mL} 0.1 \mathrm{~N} \mathrm{NaOH} / \mathrm{mL}$ urine; ${ }^{\mathrm{d} ;}$ Ratio of [analyte]/[creatinine]; ${ }^{\mathrm{e} ;}$ Value $\times 10^{-9}$ 
Table 4. Effect of dietary magnesium on histamine release in heparinized whole blood

\begin{tabular}{|c|c|c|c|c|c|c|}
\hline & \multicolumn{3}{|c|}{ \% Dietary Magnesium } & \multicolumn{3}{|c|}{$\mathrm{PV}_{\text {Value }}{ }^{\mathrm{a}}$} \\
\hline & 0.06 & 0.12 & 0.18 & SEM $^{b}$ & Lin & Quad \\
\hline Total Release ${ }^{\mathrm{c}, \mathrm{d}}$ & 10.1 & 12.7 & 14.6 & 2.84 & 0.14 & 0.86 \\
\hline Spontaneous Release ${ }^{c, e}$ & 1.1 & 2.3 & 1.3 & 0.41 & 0.68 & 0.21 \\
\hline Total $\mathrm{c}, \mathrm{f}$ & 11.0 & 15.1 & 15.9 & 2.43 & 0.11 & 0.70 \\
\hline
\end{tabular}

Table 5. Plasma concentration (nmol/g) of amino acids with dietary magnesium treatment

\begin{tabular}{|c|c|c|c|c|c|c|}
\hline \multirow[b]{2}{*}{ Amino acid } & \multicolumn{3}{|c|}{ \% Dietary Magnesium } & \multicolumn{3}{|c|}{ P-Value ${ }^{*}$} \\
\hline & 0.06 & 0.12 & 0.18 & $\mathrm{SEM}^{\mathrm{a}}$ & Lin & Quad \\
\hline Valine & 98 & 97 & 103 & 9.17 & 0.28 & 0.20 \\
\hline Leucine & 84 & 82 & 90 & 8.94 & 0.23 & 0.09 \\
\hline Isoleucine & 47 & 46 & 48 & 3.76 & 0.37 & 0.23 \\
\hline Methionine & 52 & 47 & 54 & 4.47 & 0.81 & 0.07 \\
\hline Threonine & 88 & 83 & 90 & 8.25 & 0.37 & 0.01 \\
\hline Phenylalanine & e 70 & 62 & 70 & 7.35 & 0.89 & 0.09 \\
\hline Lysine & 75 & 77 & 83 & 7.19 & 0.09 & 0.33 \\
\hline Histidine & 91 & 83 & 89 & 10.07 & 0.92 & 0.02 \\
\hline Tryptophan & 47 & 43 & 49 & 5.42 & 0.53 & 0.03 \\
\hline Alanine & 397 & 360 & 391 & 51.30 & 0.95 & 0.35 \\
\hline Glycine & 308 & 285 & 313 & 27.26 & 0.35 & 0.15 \\
\hline Proline & 135 & 124 & 131 & 16.64 & 0.79 & 0.38 \\
\hline Serine & 151 & 135 & 134 & 18.32 & 0.44 & 0.11 \\
\hline Aspartate & 14 & 13 & 14 & 1.00 & 0.71 & 0.08 \\
\hline Glutamate & 38 & 31 & 31 & 5.11 & 0.30 & 0.25 \\
\hline Glutamine & 323 & 281 & 292 & 27.74 & 0.39 & 0.11 \\
\hline Arginine & 113 & 116 & 130 & 32.57 & 0.35 & 0.53 \\
\hline Tyrosine & 45 & 41 & 44 & 4.09 & 0.61 & 0.12 \\
\hline
\end{tabular}

\section{DISCUSSION}

Magnesium has been implicated in modulating cellular events involved in inflammation (Mazur et al., 2007) and limited $\mathrm{Mg}$ has been associated with increased histamine production in rats (Malpuech-Brugere, 2000). Magnesium deficient rats exhibited peripheral vasodilatation of the ears associated with an elevation in blood histamine levels resulting from elevated mast cell degranulation (Nishio et al., 1987). Sprague-Dawley rats fed $0.05 \% \mathrm{Mg}$ diet increased blood histamine 4 to 5 fold ( 60 to $80 \mu \mathrm{g} / 100 \mathrm{~mL} \mathrm{Vs} \sim 10 \mu \mathrm{g} / 100 \mathrm{~mL}$ ) compared with controls; furthermore, mast cell number and extent of degranulation were increased with a $\mathrm{Mg}$ deplete diet (Kraeuter and Schwartz, 1980). Magnesium deficiency causes leukocytosis in rats with infiltration of tissues such as heart, lung, skeletal muscle, intestine and thymus, but accumulation of eosinophil occurs in certain tissues: Urinary tract and gastrointestinal tract, suggesting heightened sensitivity (Mazur et al., 2007) and these cells are not only increased in number, they are primed for action. Magnesium depleted rats demonstrate elevated levels of pro-inflammatory cytokines (e.g., IL-6 and high sensitivity $\mathrm{C}$ reactive protein) and demonstrated increased plasma substance P (Mazur et al., 2007; Song et al., 2007).

The mechanistic link between $\mathrm{Mg}$ deficiency and inflammation likely includes calcium signaling, neurotransmitter release of substance $\mathrm{P}$, membrane oxidation and activation of Nuclear Factor kappa B (NFkB) (Mazur et al., 2007). In vitro work has shown that there is an increased response of $\mathrm{Mg}$ depleted cells to calcium signaling (Malpuech-Brugere et al., 1998), but $\mathrm{Mg}$ acts a natural antagonist of calcium and it is likely that decreased extracellular $\mathrm{Mg}$ induces an increase in intracellular calcium (Mazur et al., 2007). Furthermore, $\mathrm{Mg}$ deficiency alters the stress response by affecting neuromediator activity or production of acetylcholine, catecholamine and substance $P$, implicating the deficiency strongly in neurogenic inflammation (Mazur et al., 2007). Lastly, NFאB is an important family of transcription factors which, when activated, translocate to the nucleus and stimulate transcription of genes that control immune and inflammatory responses (Altura et al., 2003). It has been shown that low extracellular $\mathrm{Mg}$ induces lipid peroxidation and activation of $\mathrm{NF \kappa B}$ in cultured canine cerebral vascular smooth muscles cells and supports a potential role for $\mathrm{NF} \kappa \mathrm{B}$ in $\mathrm{Mg}$ deficient inflammation (Altura et al., 2003).

The oxidative stress placed on the cellular environment due to inflammation is vast and affects tissue, erythrocyte and lipoprotein peroxidation, oxidative modification of proteins, antioxidant status reduction and elevated plasma Nitric Oxide (NO) (Mazur et al., 2007). An example of this inflammatory and oxidative stress is seen in the development of cardiac lesions in experimentally $\mathrm{Mg}$ deprived rodents subjected to ischemic-reperfusion stress (Tejero-Taldo et al., 2004). It 
was found that treatment with antioxidants (Vitamin E and porbucol) significantly protected against lesion development. Non-protected rat cardiac muscle generated excess NO when exposed to ischemic-reperfusion stress, which contributed to lesion formation (TejeroTaldo et al., 2004). Substance P released from c-fibers is implicated in neurogenic inflammation and when NMDA receptors (participatory in substance $P$ release from c fibers) were blocked, perivascular inflammatory infiltrates were reduced and cardiac lesion formation was reduced (Tejero-Taldo et al., 2004).

Urinary histamine appears to be primarily produced in the cortical glomeruli of the kidney from circulating plasma histidine via histidine decarboxylase (Abboud et al., 1982). This has been confirmed in cultured cortical glomerular cells incubated with L-Histidine and has been attributed as the major site of intra-renal histamine synthesis and accumulation (Abboud et al., 1982). Very small concentrations of circulating plasma histamine stimulate the accumulation of cAMP in the glomeruli and increase filtration rate, but much lower concentrations exist in plasma (Abboud et al., 1982). In the current experiment, a quadratic effect was seen on $24 \mathrm{~h}$ urinary histamine excretion demonstrating that with increased dietary $\mathrm{Mg}$, domestic felines generate elevated histamine levels in urine. However, when histamine concentration was normalized to creatinine concentration no treatment differences were detected. Creatinine is a metabolite of creatine metabolism in skeletal muscle; it is freely filtered across the glomerulus and is not reabsorbed, secreted, or metabolized by any cell type in the nephron and can be used for normalization of renal filtered or excreted analytes (Koeppen and Stanton, 2008). The inconsistent results between $24 \mathrm{~h}$ histamine excretion rate and histamine: Creatinine in the current experiment are not obvious. Given that histamine and creatinine exhibited a similar pattern for both urinary concentration and excretion rate it may suggest that excretion rate was complicated by either incomplete urine recovery or frequency of urination. Not all cats voided during the 24 $\mathrm{h}$ urine collection period and thus the first subsequent voiding was used as the $24 \mathrm{~h}$ output. Although felines usually urinate multiple times daily, it is not uncommon for them to withhold urine for multiple days during balance studies (Burger and Smith, 1987; Matandos and Franz, 1980). Previous efforts using ${ }^{14} \mathrm{C}$-labelled inulin, a non-metabolized and rapidly excreted compound, indicate that multiple days of urine collection are necessary for accurate quantitative measures of urinary metabolite excretion (Hendriks et al., 1999). The observed data does not agree with the experimental hypothesis that decreased levels of dietary $\mathrm{Mg}$ would be associated with elevated levels of histamine in urine as would be consistent with rat models. However, in murine models, dietary treatments below $\mathrm{Mg}$ requirement were provided (Mazur et al., 2007; Song et al., 2007); the current study did not utilize a diet below $\mathrm{Mg}$ requirement. However, normal physiological plasma $\mathrm{Mg}$ levels are between 0.8 and $1.2 \mathrm{mmol} \mathrm{L}^{-1}$ in felines, but may reach as low as $0.4 \mathrm{mmol} \mathrm{L}^{-1}$ (Altura and Altura, 1984; Kaneko et al., 1997; Rude and Singer, 1981); our data fall below the normal plasma $\mathrm{Mg}$ values expected in felines, but elevations in urine histamine were still not seen. It is not surprising that histamine levels are not altered in plasma, as histamine can be rapidly catabolized and cleared from plasma (Schayer et al., 1954). Magnesium exists within all intracellular compartments and is primarily $(80-90 \%)$ bound to ATP (Rude, 1998). The principle role of Mg is related to enzyme activity; there are over 300 enzyme systems, which are dependent on association with $\mathrm{Mg}$ and of great interest, all enzymes requiring ATP, require $\mathrm{Mg}$ for substrate formation (Rude, 1998). Furthermore, intracellular free $\mathrm{Mg}$ acts as an allosteric activator of enzyme action (e.g., adenylate cyclase, phospholipase $\mathrm{C}$ and $\mathrm{Na} / \mathrm{K}$-ATPase) (Connolly et al., 1985; Dorup and Clausen, 1993; Garfinkel and Garfinkel, 1985; Maguire, 1984).

Our diets were formulated well above minimum amino acid requirements and our plasma amino acid concentrations were comparable to those found in felines fed to $100 \%$ minimum amino acid requirement (Biourge et al., 1994). Plasma lysine concentrated tended to increase linearly with dietary $\mathrm{Mg}$. However, plasma concentrations of threonine, histidine and tryptophan demonstrated a quadratic effect with dietary treatment and leucine, methionine, phenylalanine and aspartate exhibited quadratic trends with dietary treatment. The quadratic responses of these amino acids to dietary treatment can be characterized as a decrease plasma concentration for the intermediate $(0.12 \%)$ dietary $\mathrm{Mg}$ treatment. The dietary composition of the intermediate treatment does not reflect any depression in crude protein or amino acid content compared to the other treatments. Individual observations do not indicate any outlying cats in the dietary treatment means, which might skew the data. It is unclear based on the data collected in this experiment what underlying mechanism may be contributing to these effects.

\section{CONCLUSION}

In adult spayed female domestic cats, $0.06,0.12$, $0.18 \%$ dietary $\mathrm{Mg}$ did not affect urine output or acidity. Urinary histamine excretion rate was elevated in cats fed 
$0.18 \% \mathrm{Mg}$, however, when urinary histamine concentration was normalized to creatinine, no differences were observed between dietary treatments. In contrast to previous observations in rodents fed $\mathrm{Mg}$ deficient diets, dietary $\mathrm{Mg}$ supplied at or above requirement did not alter circulating concentrations of histamine. Moreover, dietary $\mathrm{Mg}$ did not influence total or antigen-induced histamine release in whole blood. Based on the above findings, our hypothesis that low levels of dietary $\mathrm{Mg}$ would elevate plasma and urine histamine concentration in felines was rejected. Accordingly, it seems unlikely that alterations of dietary $\mathrm{Mg}$, within the aforementioned ranges, would alter the histamine inflammatory status of the domestic feline significantly contributing to idiopathic cystitis.

\section{REFERENCES}

AOAC, 2005. Official Methods of Analysis. 18th Edn., Association of Official Analytical Chemists, Gaithersburg, MD.

Abboud, H.E., S.L. Ou, J.A. Velosa, S.V. Shah and T.P. Dousa, 1982. Dynamics of renal histamine in normal rat kidney and in nephrosis induced by aminonucleoside of puromycin. J. Clin. Invest., 69: 327-336. DOI: 10.1172/JCI110456

Altura, B.M., A. Gebrewold, A. Zhang and B.T. Altura, 2003. Low extracellular magnesium ions induce lipid peroxidation and activation of nuclear factorkappa B in canine cerebral vascular smooth muscle: Possible relation to traumatic brain injury and strokes. Neuros. Lett., 341: 189-192. DOI: 10.1016/S0304-3940(03)00134-4

Altura, B.T. and B.M. Altura, 1984. Interactions of Mg and $\mathrm{K}$ on cerebral vessels-Aspects in view of stroke. Review of Present Status and new findings. Magnesium, 3: 195-211. PMID: 6399342

Bartges, J.W. and C.A. Kirk, 2006. Nutrition and lower urinary tract disease in cats. Vet. Clin. North Am. Small Anim. Pract., 36: 1361-1376. DOI: 10.1016/j.cvsm.2006.08.006

Biourge, V., J.M. Groff, C. Fisher, D. Bee and J.G. Morris et al., 1994. Nitrogen balance, plasma free amino acid concentrations and urinary orotic acid excretion during long-term fasting in cats. J. Nutr., 124: 1094-1103. PMID: 8027861

Burger, I.H. and P.M. Smith, 1987. Effects of diet on the characteristics of the cat. nutrition, malnutrition and dietetics in the dogs and cat. Proceedings of the International Symposium, (IS' 87), Hanover, Germany, pp: 71-73.
Calder, A.G., K.E. Garden, S.E. Anderson and G.E. Lobley, 1999. Quantitation of blood and plasma amino acids using isotope dilution electron impact gas chromatography/mass spectrometry with $\mathrm{U}_{-}{ }^{13} \mathrm{C}$ amino acids as internal standards. Rapid Commun. Mass Spectrometry, 13: 2080-2083. DOI: 10.1002/(SICI)1097-

0231(19991115)13:21<2080::AID-

RCM755>3.0.CO;2-O

Connolly, T.M., T.E. Bross and P.W. Majerus, 1985. Isolation of a phosphomonesterase from humanplatelets that specifically hydrolyzes the 5Phosphate of Inositol 1, 4, 5-Trisphosphate. J. Biol. Chem., 260: 7868-7874. PMID: 2989264

Dorup, I. and T. Clausen, 1993. Correlation between magnesium and potassium contents in muscle: Role of $\mathrm{Na}(+)-\mathrm{K}+$ pump. Am. J. Physiol. Cell Physiol., 264: C457-C463. PMID: 8383433

El-Kadi, S.W., R.L. Baldwin, N.E. Sunny, S.L. Owens and B.J. Bequette, 2006. Intestinal protein supply alters amino acid, but not glucose, metabolism by the sheep gastrointestinal tract. J. Nutr., 136: 12611269. PMID: 16614414

Galoppin, L., C. Noirot, J.P. Wastiaux, P. Scheinmann and J. Paupe et al., 1989. Comparison between number of basophils, blood histamine and histamine release in cancer and noncancer patients. J. Allergy Clin. Immunol., 84: 501-506. DOI: 10.1016/00916749(89)90363-1

Garfinkel, L. and D. Garfinkel. 1985. Magnesium regulation of the glycolytic pathway and the enzymes involved. Magnesium, 4: 60-72. PMID: 2931560

Hendriks, B.W.H., S. Wamberg and M.F. Tarttelin, 1999. A metabolism cage for quantitative urine collection and accurate measurement of water balance in adult cats (Felis catus). J. Anim. Physiol. Anim. Nutrit., 82: 94-105. DOI: 10.1111/j.14390396.1999.00214.x

Kaneko, J.J., J.W. Harvey and M.L. Bruss, 1997. Clinical Biochemistry of Domestic Animals. 5th Edn., Gulf Professional Publishing, San Diego, ISBN-10: 0123963052, pp: 932.

Koeppen, B.M. and B.A. Stanton, 2008. Berne and Levy Physiology. 6th Edn., Mosby, Philadelphia, ISBN10: 0323045820, pp: 834.

Kraeuter, S.L. and R. Schwartz, 1980. Blood and mast cell histamine levels in magnesium-deficient rats. J. Nutr., 110: 851-858. PMID: 6445415

Maguire, M.E., 1984. Hormone-sensitive magnesium transport and magnesium regulation of adenylatecyclase. Trends Pharmacol. Sci., 5: 73-77. DOI: 10.1016/0165-6147(84)90372-9 
Malpuech-Brugere, C., 2000. Inflammatory response following acute magnesium deficiency in the rat. Biochim. Biophys. Acta, 1501: 91-98. DOI: 10.1016/S0925-4439(00)00018-1

Malpuech-Brugere, C., E. Rock, C. Astier, W. Nowacki and A. Mazur et al., 1998. Exacerbated immune stress response during experimental magnesium deficiency results from abnormal calcium homeosatasis. Life Sci., 63: 1815-1822. DOI: 10.1016/S0024-3205(98)00455-X

Matandos, C.K. and D.R. Franz, 1980. Collection of urine from caged laboratory cats. Laboratory Anim. Sci., 30: 562-564. PMID: 7431857

Matsui, T., 2007. New Perspectives in Magnesium Research: Nutrition and Health. In: Significance of Magnesium in Animals, Nishizawa, Y., H. Morii, J. Durlach, (Eds.), Springer, ISBN-10: 184628483X, London, pp: 381-391.

Mazur, A., J.A. Maier, E. Rock, E. Gueux and W. Nowacki et al., 2007. Magnesium and the inflammatory response: Potential physiopathological implications. Arch Biochem. Biophys., 458: 48-56. DOI: 10.1016/j.abb.2006.03.031

Myers, G.L., 2006. Recommendations for improving serum creatinine measurement: A report from the laboratory working group of the national kidney disease education program. Clin. Chem., 52: 5-18. DOI: $10.1373 /$ clinchem.2005.0525144

Nishio, A., S. Ishiguro and N. Miyao, 1987. Specific change of histamine metabolism in acute magnesium-deficient young rats. Drug Nutr. Interact., 5: 89-96. PMID: 3111814
NRC, 2003. Nutrient Requirements of Dogs and Cats. 1st Edn., National Academies Press, Washington, ISBN-10: 0309086280, pp: 5.

Rude, R.K. and F.R. Singer, 1981. Magnesium deficiency and excess. Annu. Rev. Med., 32: 245259. DOI: 10.1146/annurev.me.32.020181.001333

Rude, R.K., 1998. Magnesium deficiency: A cause of heterogenous disease in humans. J. Bone Mineral Res., 13 : $749-758 . \quad$ DOI: 10.1359/jbmr.1998.13.4.749

Schayer, R.W., K.Y. Wu and R.L. Smiley, 1954. Sources of urinary histamine in the rat. Am. J. Physiol., 179: 481-485. PMID: 13228614

Song, Y., T.Y. Li, R.M. Van Dam, J.E. Manson and F.B. $\mathrm{Hu}$, 2007. Magnesium intake and plasma concentrations of markers of systemic inflammation and endothelial dysfunction in women. Am. J. Clin. Nutr., 85: 1068-1074. PMID: 17413107

Tejero-Taldo, M.I., G. Chmielinska, G. Gonzalez, I.T. Mak and W.B. Weglicki, 2004. N-Methyl-Daspartate receptor blockade inhibits cardiac inflammation in the Mg-deficient rat. J. Pharmacol. Exp. Ther., 311: 8-13. DOI: 10.1124/jpet.104.070003 